\title{
The Desirability of the Use of Technology to Prevent Social Isolation of Older Adults
}

\author{
Matias Garcia-Constantino \\ School of Computing \\ Ulster University \\ Jordanstown, UK \\ m.garcia-constantino@ulster.ac.uk \\ Austen Burns \\ Centre for Independent Living NI \\ Belfast, UK \\ austen@cilni.org
}

\author{
Jonathan Synnott \\ School of Computing \\ Ulster University \\ Jordanstown, UK \\ j.synnott@ulster.ac.uk
Mike Little
RF Proximity
Belfast, UK
michael@iotiger.net

\author{
Chris Nugent \\ School of Computing \\ Ulster University \\ Jordanstown, UK \\ cd.nugent@ulster.ac.uk \\ Deepak Samson \\ Connected Care Solutions \\ Belfast, UK \\ deepak.samson@connectedcaresolutions.co.uk
}

\begin{abstract}
As life expectancy has increased, more older adults are experiencing social isolation, which can increase the risk of several negative effects on their health. The use of technology by older adults can support the prevention of social isolation by enabling them to be proactive and motivated to establish human interactions with relatives and friends. This paper explores and presents the results of a survey administered to $\mathbf{7 4}$ people from the Centre for Independent Living NI (CILNI) to identify the prevalence of social isolation in Northern Ireland, and the desirability to use technology to prevent it. This paper also introduces an upcoming trial into the use of technology for the prevention of social isolation for older adults living alone.
\end{abstract}

\section{Social Isolation, Older Adults, Technology Adoption, Digital Technology}

\section{INTRODUCTION}

Social isolation can affect people from different age groups but elderly people are considered to be more at risk due to the loss of their partner, family, reduced mobility, geographical isolation or limited income. As of 2012 it was estimated that among elderly people in the UK, $12 \%$ reported isolation (SCIE, 2012), and that figure was predicted to increase in the following years. Loneliness can be considered as an emotional response to isolation. According to Victor et al. (2005), there are four main areas of risk factors for loneliness: (i) sociodemographic, (ii) material, (iii) health, and (iv) social resources.

Regarding human health, social isolation can increase the risk of: (i) developing cardiovascular disease, (ii) infectious illness, (iii) cognitive deterioration, (iv) elevated blood pressure, (v) heightened inflammatory and metabolic responses to stress, and (vi) mortality (reduction of life expectancy) (Steptoe et al., 2013). While the negative effects of social isolation in healthy people can be acknowledged, the effects on people with long standing illnesses could cause a rapid deterioration on their health, also having repercussions on personal and organisational health care costs. The Office of the First Minister and Deputy First Minister (OFMDFM) of Northern Ireland Statistics and Research Branch reported in 2015
(OFMDFM, 2015) that the proportion of older people with a long standing illness was $61 \%$ of $65-74$ year olds and $69 \%$ of those aged $75+$.

Regarding the use of technology, the OFMDFM Statistics and Research Branch reported that the proportion of older people with access to the internet was $69 \%$ of $60-69$ year olds and $40 \%$ of those aged 70+ (OFMDFM, 2015). In relation to mobile phone ownership, the same report (OFMDFM, 2015) mentioned that $82 \%$ of those aged $60+$ owned a mobile phone. These figures are a good indicator that in general the use of technology could be well accepted by healthy older adults from the age of 60 years old or older with no cognitive conditions or learning disabilities living in isolation.

There is a potential for using technology specifically to prevent social isolation, however, more information is required to know the technology appetite and profile of people suffering from social isolation. Thus, as part of this research work we designed a survey to investigate how familiar people are with technology and their opinion of potential benefits of using technology to support independent living and to improve their quality of life.

The remainder of the paper is organised as follows: Section 2 presents the related work on the use of technology to prevent and reduce social isolation in older adults. Section 3 describes a survey about the 
use of technology focusing on older adults living alone and Section 4 presents the results obtained. Section 5 introduces an upcoming trial to use technology to prevent social isolation. Finally, Section 6 presents the conclusions.

\section{RELATED WORK}

This section considers research work relevant to social isolation in the context of the use of technology by older adults. Social isolation and loneliness have been extensively covered in the literature. It is important to make the distinction between social isolation and loneliness. Steptoe et al. (2013) define social isolation as "an objective and quantifiable reflection of reduced social network size and paucity of social contact". Loneliness, on the other hand, can be considered as an emotional response to isolation.

In the study presented by Lowenthal (1964) in the early 1960 s, the relation between social isolation and mental illness in old age was investigated. Note that while social isolation in the elderly was of interest as a societal problem back then, to our best knowledge there were no studies that involved the use of technology until the early 2000s.

Magnusson et al. (2004) presented a literature review study of the role of Information and Communication Technology (ICT) to support older people living at home and their family carers. Magnusson et al. (2004) concluded that the reviewed literature then focused on telehealth and telecare applications in the home. They noted the importance of the design of the technologies as well as the attitudes of older people towards technology and training in using technology.

A more recent literature review about the role of ICT to reduce social isolation in the elderly was presented by Chen and Schulz (2016), in which they state that while ICT could be effective to reduce social isolation among the elderly, it may not be adopted by every older adult. The previous statement was supported by the high attrition rate of participants in the studies reviewed as well as by inconclusive results of the effect of ICT in social isolation in the elderly. Chen and Schulz (2016) concluded that ICT interventions should be tailored to the users in order to obtain the best effects.

Note that the literature review presented by Chen and Schulz (2016) was published almost a decade after the one presented by Magnusson et al. (2004). In that period of time there has been a rapid development in ICT which has benefitted the general public with, among other things, the availability of: (i) affordable, portable and user friendly devices (smartphones and tablets), (ii) software for text and video communication, and (iii) faster connection to the Internet.
Pedell et al. (2010) described a set of design requirements for technology to reduce social isolation in older people. The requirements are based on a study that involved an expert survey, a field study and a design workshop. Baecker et al. (2014) presented the iterative design process of InTouch, a mobile app for older adults to connect with their family and friends by sending photos, videos, audio messages and "waves" (short messages). Baecker et al. (2014) mention, similarly to Chen and Schultz (2016), the importance of tailored based usability and accessibility designs.

In the study presented by Karimi and Neustaedter (2012), communication practices of older adults in the digital age in the context of social isolation were investigated and some of their findings are that while older adults are reluctant on using new technologies, social media is seen as useful. Interestingly, Aarts et al. (2015) concluded in their study that an association between Social Network Sites (SNS) usage by older adults and loneliness cannot be automatically assumed.

In the work by Heart and Kalderon (2013) a questionnaire was used to investigate healthrelated ICT adoption by older adults, which indicated that technology should be simple to use and should have a good justification in terms of benefits to the users. Hill et al. (2015) presented a study on the experiences and perceptions of older adults with digital technology. Hill et al. (2015) reported that while older adults acknowledged the advantages of digital technology, they recognised that it can also disempower if they do not have the appropriate skills for its use.

From the research work reviewed in this section it is clear that there is a need to have tailored, user friendly and dedicated technologies (devices and software) to prevent and reduce the social isolation of older adults.

\section{TECHNOLOGY OPINION SURVEY AND SOCIAL ISOLATION}

The Technology Opinion Survey used was designed by researchers at the Northern Ireland Connected Health Innovation Centre (NI-CHIC) (NICHIC, 2018) and the Smart Environments Research Group (SERG) at Ulster University to investigate the use of technology in the home to promote independent living and increased quality of life for people with a wide range of conditions. The Technology Opinion Survey was designed to be simple but informative. It is comprised by ten questions and divided into two parts: (i) general information about the person (first five questions), and (ii) opinion about technology (last five questions). 
In addition to the survey, the respondents were presented with an information sheet about an upcoming study on the use of technology to reduce social isolation and a basic contact details form in case they were interested in more information or in taking part. The survey has been initially available to users of the Centre for Independent Living NI (CILNI) (CILNI, 2018) in the form of hard copy and online. CILNI is a charitable organisation from Northern Ireland that provides a range of services to disabled people, including older people, people with learning disability and mental health service users. It is planned to contact other organisations of which their users can benefit from our research about technology opinion and social isolation.

\section{RESULTS OF THE TECHNOLOGY OPINION SURVEY RELATED TO SOCIAL ISOLATION}

The Technology Opinion Survey was completed by 74 users of CILNI. Table 1 shows the distribution of respondents by age group.

Table 1: Survey respondents distribution by age group.

\begin{tabular}{|c|c|c|}
\hline $\begin{array}{c}\text { Age group } \\
\text { (years) }\end{array}$ & Count & Percentage (\%) \\
\hline $0-14$ & 1 & 1.35 \\
\hline $15-24$ & 4 & 5.41 \\
\hline $25-44$ & 11 & 14.86 \\
\hline $45-64$ & 35 & 47.30 \\
\hline $65+$ & 23 & 31.08 \\
\hline
\end{tabular}

The two age groups that are of interest in the context of the social isolation study are 45-64 years old and 65+ years old, which are $47.30 \%$ and $31.08 \%$ from the total number of respondents respectively. Combined, both groups make the $78.38 \%$ from the total number of respondents.

Note that the purpose of the questions included in the survey was to gather general information about the users and their opinion about technology. There were no questions or references related to social isolation in the survey apart from the information sheet about the upcoming social isolation project, which was presented to the users after they completed the survey.

It is then interesting that many users mentioned social isolation, communication and contact with family and friends in their answers for open ended questions. To the survey question of "what support needs do you currently have?" (with respect to technology) 21 users mentioned in their answers: "contacting family and friends", "keep in touch with family/friends/people" and "communication with family/friends/people". An interesting response from a user in the 45-64 years old age range was:
"It prevents me from becoming completely isolated, I can keep in touch with friends and family in a way that would otherwise be impossible".

Two dichotomous (yes/no) questions of the survey asked the users if they thought technology could help them to (i) live and independent life, and (ii) improve their quality of life. If the users replied "yes" to any of the questions they were then asked to mention the ways in which technology helped them. In relation to social isolation, 23 users mentioned in their answers: "contacting family and friends", "keep in touch with family/friends/people" and "communication with family/friends/people".

Regarding the survey question "If you are currently using technology in some way to help you, what ways are you using it?", an interesting response from a user in the 65+ years old age range was:

"Keep in touch with family and friends through the world using my smartphone and laptop. It means I don't feel isolated and feel I have support from them".

The last question of the survey asked "do you have any other comments about what may be preventing you from using more technology to assist with your needs?". From the responses to this question, three areas which contribute to make the respondents to feel socially isolated were identified: (i) lack of support and training to use technology, (ii) lack of financial resources to obtain devices (smartphones, tablets and laptops), and (iii) physical disabilities.

Regarding the lack of support and training to use technology, two responses from users in the 65+ years old age range stand out:

"I do what I can on a smartphone but it gets broken regularly and I go for months with no access to anything as I no longer have a laptop or tablet. It can be very isolating and makes me much more reliant on others".

"I have nobody to ask for help. All of this magnifies my feelings of isolation and being left out, left behind, missing out. I know I am capable of learning but I can't do it by myself".

These responses show how not having access to basic support and training to use technology can be frustrating and discouraging for users, as well as considerably aggravating their social isolation.

In relation to lack of financial resources to obtain devices and make use of technology, two interesting responses, from users in the 45-64 and $65+$ years old age range, were:

"I wish that technology could be made more financially available". 
"No money for contract, no money to replace existing tech stuff i.e. antique mobile and old laptop and very basic TV".

In Section 1 it was mentioned that $82 \%$ of people aged $60_{+}$in Northern Ireland owned a mobile phone (OFMDFM, 2015). For the rest of the older people that have no mobile phone, tablet or laptop, there could be a real lack of financial resources but also a perception of devices being costly due to disinformation. In this case it would be required to provide older people with advice on the most adequate and affordable device they should get, as well as information of charities that could support them in case they cannot afford to buy the devices.

In terms of physical disabilities as limitations for the use of technology, a user in the 45-64 years old age range stated:

\section{"Cannot use my arm, hands or feet for more than a couple of minutes at a time due to weakness and pain".}

Note that $25 \%$ of CILNI users have some type of physical disability. In other questions of the survey many users indicated that the use of technology has been useful in their daily lives and has helped them to be more independent. It is important to acknowledge that older adults have individual requirements, regardless of having a physical disability, that need to be considered to enable them to make the best use of technology. Assistive technology must be used to support users with impairments such as mobility, visual, hearing and cognitive.

\section{SOCIAL ISOLATION PROJECT}

It is acknowledged that social isolation is a societal problem that does not exclusively affect older adults. However, in the context of the use of technology to improve their daily lives, older adults tend to have less experience and knowledge in the use of technology with respect to younger people.

The upcoming trial into the use of technology for the prevention of social isolation for older adults living alone is part of the NI-CHIC project. Four organisations are involved: RF Proximity (RF Proximity, 2018), Connected Care Solutions, CILNI and Ulster University.

This trial is a feasibility study which has four aims:

(i) To reduce social isolation and to increase assurance and wellbeing for older adults living alone in their own home.

(ii) To effectively combine Connected Care Solutions' product Ethel, wireless sensors developed by RF Proximity and smart plugs used for research at Ulster University. (iii) To recruit 20 participants from CILNI and from other organisations that support the wellbeing of the elderly.

(iv) To generate datasets that will be analysed to give insight into the benefits of using these technologies to reduce social isolation and to increase assurance and wellbeing for older adults.

Connected Care Solutions' product Ethel (Connected Care Solutions, 2018) is a large touch screen device designed for the elderly which, among many other features, includes: video calling, medication reminders, e-mail and text messaging, automated alerts, and daily surveys about social isolation and wellness. RF Proximity's considered sensors measure: temperature, humidity, light, smoke and carbon monoxide. The smart plugs used at Ulster University are for monitoring common electric appliances (television and kettle) usage.

Daily short surveys about the participants' Ioneliness perception and wellbeing (alternated by day) will be presented on the Ethel device during the study. The surveys about loneliness will include questions from short tools and scales used to measure loneliness (Campaign to End Loneliness, 2011):

- The Campaign to End Loneliness Measurement Tool (3 questions)

- De Jong Gierveld Loneliness Scale (6 questions)

- The UCLA Loneliness Scale (3 questions)

- Single-Item 'Scales' (1 question)

Participants will be divided 4 into groups. For each group data from sensors and from daily surveys will be collected over 2 weeks. Participants will be sent notifications to encourage communication with relatives and friends by video or voice call.

\section{CONCLUSIONS}

This paper has presented the results of a survey about the use of technology in the context of social isolation. Three areas which contribute to make the respondents to feel socially isolated were identified: (i) lack of support and training to use technology, (ii) lack of financial resources to obtain devices, and (iii) physical disabilities. The responses related to social isolation confirmed the need of more research work on the use of technology to enable older adults to address this societal challenge. An upcoming trial into the use of technology for the prevention and reduction of social isolation of older adults living alone was introduced and described. 


\section{ACKNOWLEDGMENT}

Invest Northern Ireland is acknowledged for supporting this project under the Competence Centre Programs Grant RD0513853 - Connected Health Innovation Centre.

\section{REFERENCES}

Aarts, S., Peek S. T. M., and Wouters E. J. M. (2015). The relation between social network site usage and loneliness and mental health in community-dwelling older adults. International Journal of Geriatric Psychiatry. Vol. 30, No. 9, pp 942-949. John Wiley \& Sons.

Baecker, R., Sellen, K., Crosskey, S., Boscart, V., and Barbosa Neves, B. (2014). Technology to Reduce Social Isolation and Loneliness. Proceedings of the 16th International ACM SIGACCESS Conference on Computers \& Accessibility, pp. 27-34. ACM.

Campaign to End Loneliness (2011). Measuring Your Impact On Loneliness In Later Life. Available from:

https://www.campaigntoendloneliness.org/wpcontent/uploads/Loneliness-MeasurementGuidance1.pdf

Chen, Y. R. and Schulz, P. J. (2016). The Effect of Information Communication Technology Interventions on Reducing Social Isolation in the Elderly: A Systematic Review. Journal of Medical Internet Research. Vol. 18, No. 1.

CILNI (2018). Centre for Independent Living NI. Available from: https://www.cilbelfast.org/

Connected Care Solutions (2018). Ethel - My elderly care hub. Available from: http://myethel.co.uk/

Heart, T. and Kalderon, E. (2013). Older adults: Are they ready to adopt health-related ICT? International Journal of Medical Informatics. Vol. 82, No. 11, pp. 209-231. Elsevier.

Karimi, A. and Neustaedter, C. (2012). From high connectivity to social isolation: communication practices of older adults in the digital age. Proceedings of the ACM 2012 conference on Computer Supported Cooperative Work Companion, pp. 127-130. ACM.

Lowenthal, M. F. (1964). Social Isolation and Mental Illness in Old Age. American Sociological Review. Vol. 29, No. 1, pp. 54-70. American Sociological Association.
Magnusson, L., Hanson, E., and Borg, M. (2004). A literature review study on Information and Communication Technology as a support for frail older people living at home and their family carers. Technology and Disability. Vol. 16, No. 4, pp. 223-235. IOS Press.

Office of the First Minister and Deputy First Minister (OFMDFM). (2015). A Profile of Older People in Northern Ireland: Annual Update 2015. Available from: https://www.executiveofficeni.gov.uk/sites/default/files/publications/ofmdfm/a -profile-of-older-people-in-ni-annual-update2015.pdf

NI-CHIC (2018). Northern Ireland Connected Health Innovation Centre. Available from: http://www.ni-chic.org/

Pedell, S., Vetere, F., Kulik, L., Ozanne, E., and Gruner, A. (2010). Social isolation of older people: the role of domestic technologies. Proceedings of the 22nd Conference of the Computer-Human Interaction Special Interest Group of Australia on Computer-Human Interaction, pp. 164-167. ACM.

RF Proximity (2018). RF Proximity. Available from: http://www.rfproximity.com/

Social Care Institute for Excellence (SCIE) and Contact the Elderly (2012). Preventing loneliness and social isolation among older people. Available from: https://www.scie.org.uk/publications/ataglance/at aglance60.pdf

Steptoe, A., Shankar, A., Demakakos, P., and Wardle, J. (2013). Social isolation, loneliness, and all-cause mortality in older men and women. Proceedings of the National Academy of Sciences. Vol. 110, No. 15, pp. 5797-5801. National Academy of Sciences.

Victor, C. R., Scambler, S. J., Bowling, A., and Bond, J. (2005). The prevalence of, and risk factors for, loneliness in later life: a survey of older people in Great Britain. Ageing \& Society Journal. Vol. 25, No. 6, pp. 357-375. Cambridge University Press. 